\title{
The modulation of enzyme indoleamine 2,3-dioxygenase from dendritic cells for the treatment of type I diabetes mellitus
}

This article was published in the following Dove Press journal:

Drug Design, Development and Therapy

24 July 2017

Number of times this article has been viewed

\author{
Débora Moitinho Abram' \\ Luis Gustavo Romani \\ Fernandes ${ }^{1,2}$ \\ Antônio Celso Saragossa \\ Ramos Filho ${ }^{2}$ \\ Patrícia Ucelli Simioni ${ }^{2-4}$ \\ 'Department of Internal Medicine, \\ Faculty of Medical Sciences, University \\ of Campinas, Cidade Universitária \\ Zeferino Vaz, Campinas, SP, Brazil; \\ 2Department of Biomedical Science, \\ Faculty of Americana, Americana, \\ SP, Brazil; ' ${ }^{3}$ Department of Genetics, \\ Evolution and Bioagents, Institute \\ of Biology, University of Campinas \\ (UNICAMP), Campinas, SP, Brazil; \\ ${ }^{4}$ Department of Biochemistry and \\ Microbiology, Institute of Biosciences, \\ Universidade Estadual Paulista, UNESP, \\ Rio Claro, SP, Brazil
}

Correspondence: Patrícia Ucelli Simioni Department of Biochemistry and Microbiology, Institute of Biological Sciences, São Paulo State University, UNESP/Rio Claro, Av. 24-A, I5I 5 Bela Vista, zipcode 13506-900, Rio Claro, SP, Brazil

Tel +5519996991899

Email psimioni@gmail.com

\begin{abstract}
Diabetes mellitus type 1 (DM1) is an autoimmune disease in which $\beta$-cells of the pancreas islet are destroyed by $\mathrm{T}$ lymphocytes. Specific $\mathrm{T}$ cells are activated by antigen-presenting cells, mainly dendritic cells (DCs). It is already known that the regulation of tryptophan pathway in DC can be a mechanism of immunomodulation. The enzyme indoleamine 2,3-dioxygenase (IDO) is present in many cells, including DC, and participates in the metabolism of the amino acid tryptophan. Recent studies suggest the involvement of IDO in the modulation of immune response, which became more evident after the in vitro demonstration of IDO production by DC and of the ability of these cells to inhibit lymphocyte function through the control of tryptophan metabolism. Current studies on immunotherapies describe the use of DC and IDO to control the progression of the immune response that triggers DM1. The initial results obtained are promising and indicate the possibility of developing therapies for the treatment or prevention of the DM1. Clinical trials using these cells in DM1 patients represent an interesting alternative treatment. However, clinical trials are still in the initial phase and a robust group of assays is necessary.
\end{abstract}

Keywords: autoimmunity, immunoregulation, diabetes mellitus type 1, clinical trials, dendritic cells, indoleamine, tryptophan, tolerance

\section{Introduction}

Diabetes mellitus type 1 (DM1) is an autoimmune disease with massive destruction of pancreatic $\beta$-cells, with lymphocyte and macrophage infiltrates in the islets of Langerhans. ${ }^{1,2}$ Although already approved therapies to DM1 are available, they are still poorly effective in controlling the progression of diabetes. Recent advances in the studies of DM intended to develop cellular therapies, such as the regeneration of pancreatic $\beta$-cells from transplantation of precursor stem cells., ${ }^{3,4}$ To reverse the immunopathogenesis of the DM1, some authors propose an early vaccination as prophylaxis. Also, restoration of immune tolerance to self-antigens in DM1 patients is considered a promising therapy. ${ }^{5}$ In this sense, treatment with immunoregulatory cells specifically explores the modulatory capacity of indoleamine 2,3-dioxygenase (IDO).

It is known that the enzyme IDO, expressed in dendritic cells (DCs) and other cells, participates in the metabolism of tryptophan (TRP). Recent studies suggest the participation of IDO in the modulation of the immune response, which became more evident after the in vitro demonstration of IDO production by DC and of the ability of these cells to inhibit lymphocytes via the TRP pathway. ${ }^{6-10}$ In this subject, experiments with macrophages and human DC expressing IDO have demonstrated that the presence of IDO blocks in vitro proliferation of T cells. ${ }^{7}$ IDO1 is an immunomodulatory molecule 
with potential effects on various diseases including cancer and autoimmunity. ${ }^{11,12}$ IDO2, as well as IDO1, is implicated in TRP catabolism and modulation of immune response. IDO2 seems to act in a distinct way from IDO1. However, the specific contributions of IDO2 to physiology are still unknown. ${ }^{13}$

A recent study suggests that IDO1 activity may correlate with the pathogenesis of diabetes mellitus type 2 (DM2) since it was significantly increased in these patients. ${ }^{14}$ Reduction in IDO1 levels also seems to be related to the pathogenesis of DM1, ${ }^{15}$ since in experimental diabetes, toll-like receptor (TLR) 3-deficient mice presented a more robust disease, accompanied by the absence of IDO1 induction in pancreatic lymph nodes.

However, new mechanisms to control DM1 as well as to elucidate the participation of the IDO1 enzyme in the DC response are under development. In this context, the study of the mechanism of action of IDO1 and its relationship with the immunological mechanism can be relevant for the future development of vaccines or drugs. Hence, the aim of the present review was to describe the participation of DC in the control of the immune response on DM1, as well as the regulation of the IDO1 enzyme in these cells.

\section{Immunological mechanisms of type I diabetes mellitus}

Current studies demonstrate that DC can participate in the regulation of DM $1,{ }^{16}$ since it is a disorder related to the action of autoreactive $\mathrm{T}$ cells against pancreatic $\beta$-cells. ${ }^{17} \mathrm{CD} 11 \mathrm{c}^{+}$ $\mathrm{CD}_{11} \mathrm{~b}^{+} \mathrm{CD} 8 \alpha^{-} \mathrm{DC}$ activates $\mathrm{T}$ lymphocytes that initiate the process of insulitis and eliminates pancreatic $\beta$-cells. ${ }^{18,19}$ Autoantibodies subsequently participate in inflammatory process and can be used as markers of immune response. ${ }^{20}$ It is also known that the enzyme IDO, present in DC, participates in the immunity by regulating the proliferation of T cells. ${ }^{7}$

\section{Indoleamine 2,3-dioxygenase and the kynurenine pathway}

IDO is one of the two enzymes that catalyze the limiting step of the degradation of TRP through the kynurenine (Kyn) pathway.
Studies showed that the tryptophan 2,3-dioxygenase (TDO) and IDO enzymes catalyze the conversion of TRP to $N$-formyl kynurenine. ${ }^{21,22}$ Unlike TDO, expressed only in the liver, IDO is found in various organs, tissues, and cell types, such as stromal, hematopoietic, tumor, lymphoid, and dendritic cells, ${ }^{21,22}$ and expressed often in tissues with large mucosa, such as the gastrointestinal tract and lung. ${ }^{23}$

IDO is an oxygenase enzyme with a heme group ${ }^{24}$ composed of two domains - major and minor $^{25}$ - encoded by two closely related genes (IDO1 and IDO2), located on human chromosome $8 .{ }^{26,27}$ In the TRP catabolism, IDO is responsible for the oxidative cleavage of double bond present in the indol fraction of TRP, resulting in the formation of $\mathrm{N}$-formyl kynurenine. ${ }^{25}$ The kynurenine pathway (Figure 1) is the main route of degradation of TRP, since $99 \%$ of this ingested amino acid is metabolized by this way. The kynurenines generated include kynurenic acid, 3-hydroxykynurenine, picolinic acid, quinolinic acid, and kynurenine itself. ${ }^{25,28,29}$ IDO enzyme is able to inhibit the in vitro proliferation of $\mathrm{T}$ cells by the catabolism of TRP via kynurenines, participating in the modulation of immune response. ${ }^{30}$

Several studies indicate that the transcription process is well controlled after the activation of IDO, with activation of genes of inflammatory mediators, such as interferon (IFN)- $\alpha$, IFN- $\beta$, and IFN- $\gamma$. Among several IDO inducers, lipopolysaccharide (LPS)-induced IDO expression was found in blood, muscle, brain, liver, and lung. LPS administration induces increased concentrations of TNF- $\alpha$, IL-10, and Kyn, and a depletion of TRP indicating an elevated activity of IDO. ${ }^{28,31}$

Although IDO expression is rapidly induced by IFN- $\gamma$ alone or associated with interleukin (IL)-1 $\beta$, IDO secretion also occurs in DC after signaling by transforming growth factor beta 1 (TGF- $\beta 1$ ), which demonstrates a mediation of its regulatory function. ${ }^{7,30,32-34}$ The mechanism of control of IDO expression is not fully understood but post-translational modifications are relevant in this process. Also, the induction of IDO in DC can occur through immunomodulatory properties of molecules, that inhibit the pathways of $\mathrm{T}$ cells activation via $\mathrm{T}$ cell receptor (TCR), Cytotoxic

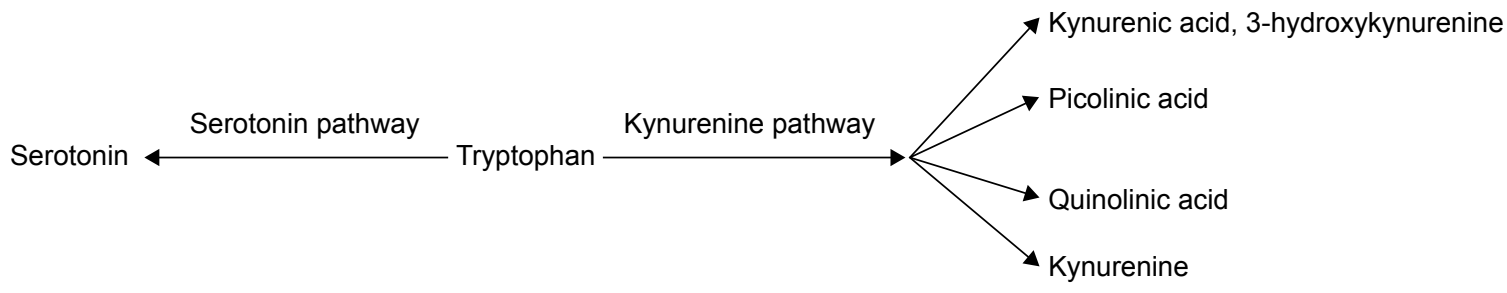

Figure I Kynurenine and serotonin pathway.

Note: Tryptophan participates in serotonin and kynurenine pathways. Data from. ${ }^{25,28-30}$ 
T-lymphocyte-Associated Associated Antigen 4 (CTLA-4), Toll like receptors (TLR) and CD40. ${ }^{23,35}$

\section{The immunoregulatory properties of IDO on DC}

The role of IDO on immunosuppression was first discussed in 1998 when Munn et al demonstrated that when pregnant rats were treated with an inhibitor of the IDO enzyme called 1-methyl tryptophan, maternal lymphocytes initiated a process of rejection to the fetus. Subsequently, the studies of IDO in immunosuppression extended to regulation of tumors, inflammatory, allergic and autoimmune diseases, the enzyme being recognized as a regulator of immunity. ${ }^{34,36,37}$ This regulatory action of IDO is possibly due to the combination of the effects of TRP degradation and of the accumulation of the kynurenine metabolites that act on the hydrocarbon ring present at the TCR. ${ }^{17,34}$

IDO can affect the ability of DC to present antigens and stimulate T cells. Also, the catabolism of the TRP is a central pathway to this immunosuppressive response. In this sense, IDO can induce the depletion of TRP and the accumulation of kynurenine metabolites, as exemplified in Figure 2. ${ }^{23,34}$ The $\mathrm{T}$ cells activated by DC expressing IDO are able to initiate the cell cycle. However, the enzymatic activity of IDO leads to a significant decrease of TRP, inducing the cell cycle arrest and enhancing $T$ cell apoptosis. IDO1 was described as the first rate-limiting enzyme acting on the degradation of TRP since the enzyme activity results in the depletion of TRP and inhibition of T lymphocytes. ${ }^{38}$ The initial step of the kynurenine pathway involves the oxidation of TRP. TRP derivatives have pleiotropic effects on homeostasis processes. IDO and TDO are heme-containing enzymes that catalyze the $\mathrm{O}_{2}$-dependent oxidation of L-TRP in biological systems. Studies report that IDO and TDO react using the same mechanism. For IDO, a ferryl species accumulates in the steady state. However, there is no evidence for the accumulation of this compound during TDO catalysis. Serotonin and melatonin are two TRP-derived compounds produced in humans, among others.

A

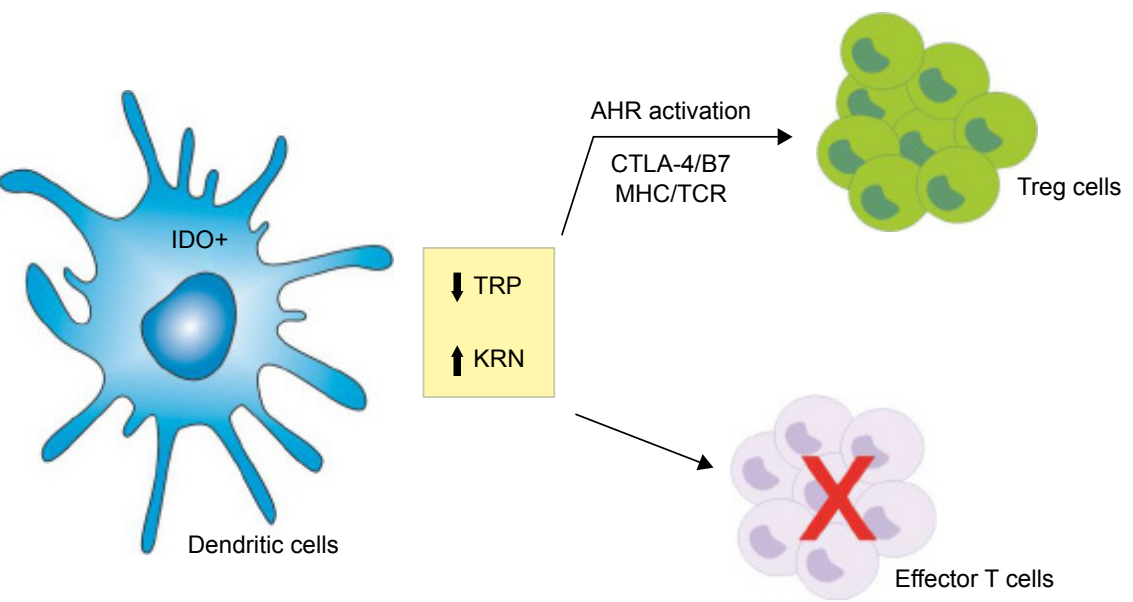

B
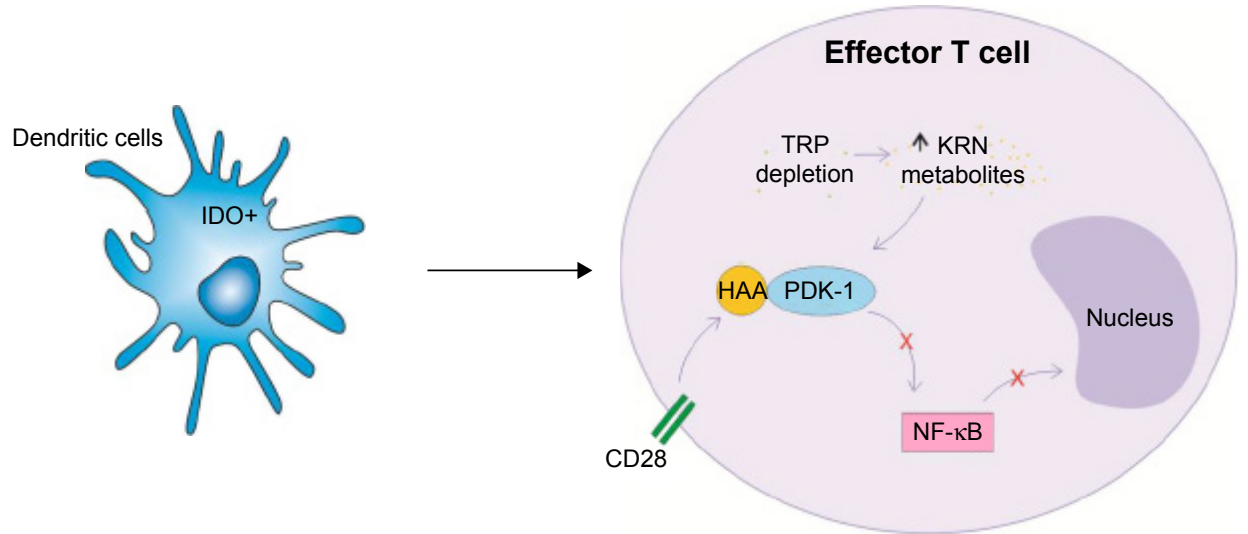

Figure 2 IDO and DC in the regulation of the T cell responses through the degradation of TRP and kynurenine metabolites.

Notes: (A) Depletion of TRP by IDO increases the metabolites of kynurenine and blocks T effector cell proliferation, favoring Treg differentiation. (B) Intracellular events in T effector cells in consequence of IDO activity in DCs.

Abbreviations: AHR, aryl hydrocarbon receptor; CTLA-4, cytotoxic T-lymphocyte-associated antigen 4; DCs, dendritic cells; HAA, 3-hydroxyanthranilic acid; IDO, indoleamine 2,3-dioxygenase; KRN, kynurenine; MHC, major histocompatibility complex; NF- KB, nuclear factor kappa B; PDK-I, phosphoinositide-dependent kinase I; TCR, T cell receptor; Treg, T regulatory; TRP, tryptophan. 
Also, indole ring breakdown through the "kynurenine shunt" produces a number of molecules involved in inflammation, immune response, excitatory neurotransmission, and many other functions, such as L-kynurenine, kynurenic and quinolinic acids, or the coenzyme nicotinamide adenine dinucleotide $\left(\mathrm{NAD}^{+}\right){ }^{39-42}$

Recent research showed that catabolism of TRP mediated by IDO inhibits the immunoregulatory kinase mammalian target of rapamycin (mTOR), with the autophagy induction. ${ }^{43}$ So, IDO was proposed to control inflammatory responses and immune tolerance coordinately by the pathways of TRP deficiency and sufficiency, via the integrated stress kinases namely general control non-depressible 2 (GCN2) and mTOR, respectively. ${ }^{43,44}$ However, the role of GCN2 in immune response and suppression is not clearly established. Conflicting data showed that, in lupus-prone mice, activation of GCN2 reduced anti-DNA antibodies, implicating GCN2 signal in limiting autoimmunity. ${ }^{45}$ However, a recent study described that kinase GCN2 is not related to the suppression of antitumor response by TRP catabolism. ${ }^{46}$

Tryptophan catabolites or starvation induce a regulatory environment affecting both $\mathrm{CD}^{+}$and $\mathrm{CD}^{+} \mathrm{T}$ cells. Recent studies showed that TRP catabolites result in GCN2 kinasedependent downregulation of the TCR zeta-chain in $\mathrm{CD}^{+}$ $\mathrm{T}$ cells in mouse model. Also, TRP catabolism includes the emergence of a regulatory phenotype in naive $\mathrm{CD} 4^{+} \mathrm{CD} 25^{-}$ T cells via TGF- $\beta$ induction of the forkhead transcription factor Foxp3, capable of controlling diabetogenic T cells. ${ }^{47,48}$

The metabolites generated by the IDO activity are potent inhibitors of $\mathrm{T}$ cell activation. Some compounds such as 3-hydroxyanthranilic acid (3-HAA) are able to block T cells by interfering in the nuclear factor kappa B (NF- $\mathrm{BB})$ pathway via inhibition of phosphoinositide-dependent kinase 1 (PDK-1), a mediator of NF- $\mathrm{KB}$ activation through CD28 signaling ${ }^{49,50}$ (Figure 2). Besides that, kynurenine is also involved in the generation of T regulatory (Treg) in periphery, another important mechanism to control $\mathrm{T}$ cell responses. In lymph nodes, IDO controls conversion of Foxp3 $3^{+}$Tregs to T helper (Th) 17 cells. ${ }^{51}$ In this way, TRP metabolites are able to ligate to aryl hydrocarbon receptor (AHR), a cytoplasmic transcription factor, favoring differentiation of naive T cells to Tregs but not to Th17 cells. ${ }^{52}$ However, literature suggests that other signaling pathways are also relevant, like the CTLA-4/B7 signaling and the major histocompatibility complex (MHC)-TCR interaction..$^{23,53}$

Related to IDO therapeutic potential, synergistic treatment with TGF- $\beta$ can result in a burst of regulatory kynurenines that contribute to establishing a state of "infectious tolerance". TGF- $\beta$ activates the tolerogenic pathway of TRP catabolism - mediated by IDO. ${ }^{54}$ IDO can be associated with the pathogenesis of persistent infections, and Treg cells might play an important role in the direct control of innate immune responses. According to an infectious tolerance model, Treg cells inhibit neutrophil function and promote their apoptosis by the induction of suppressor cell populations. LPS-activated Treg cells induce IL-10 and TGF- $\beta 1$ secretion, inhibit IL- 6 production, and also induce the expression of heme oxygenase-1 (HO-1) and the suppressor of cytokine signaling 3 molecule (SOCS3). ${ }^{55,56}$

Tregs induce IDO expression in DCs and tolerogenic $\mathrm{DC}$ induce conversion of naive $\mathrm{T}$ cells to Tregs. Both myeloid-derived suppressor cells (MDSCs) subset and tolerogenic DCs can control self-reactive immune responses by promoting the expansion of Treg population. MDSCs require direct contact with activated $\mathrm{T}$ cells, which leads to the production of IDO. ${ }^{57}$

A recent report showed that high-dose IL-4 inhibits the $\mathrm{CD} 103^{+} \mathrm{DC}$ differentiation by inducing high levels of IDO. Interestingly, IL-4 diminished IDO expression in DCs in a dose-dependent manner. DCs generated under low concentrations of IL-4 favored Treg cells differentiation, which depend on IDO produced by $\mathrm{CD} 103^{+} \mathrm{DCs}^{58}$

\section{Therapy with tolerogenic DC in diabetes mellitus}

The conventional DM therapies basically include medications to control glucose and insulin levels. However, with the wide knowledge on cell biology, immunology, and biotechnology, cell therapy has been gaining prominence. ${ }^{59}$ It can be used in the treatment of infections, autoimmune diseases, cancer, metabolic diseases, and tissue degeneration. ${ }^{59,60}$ Also, cell therapy is becoming the alternative treatment of DM1 and several studies approach this theme in different ways. ${ }^{61}$

Studies demonstrate the possibility of development of in vitro insulin-producing cells with characteristics similar to pancreatic $\beta$-cells, using embryonic stem cells as source. Replacement of pancreatic $\beta$-cells has already been considered as an alternative to treat DM1. ${ }^{62}$ Jalili et al prolonged islet allograft survival by preventing immune response. They induced a local immunosuppressive activity by stable IDO induction in bystander fibroblasts. ${ }^{63}$ Also, administration of endovenous anti-CD3 monoclonal antibodies in patients newly diagnosed with DM1 results in the reduction of circulating lymphocytes as well as C-peptide, insulin, and glycated hemoglobin (HbAL1c) values. ${ }^{64,65}$ In addition, experiments combining transplantation of autologous hematopoietic stem 
cell and immunosuppression protocol based on endovenous cyclophosphamide and anticytoplasmic globulin restarted the immune system without autoreactive memory to the regenerated pancreatic $\beta$-cells. A high percentage of patients obtained insulin independence, without mortality or new toxic effects..$^{66-68}$

Among therapies, DC therapies can be highlighted for autoimmune diseases such as DM1, since these cells participate in the pathogenesis of this disease. ${ }^{69,70} \mathrm{DC}$ therapies are evaluated for the treatment of infectious diseases, tumor, autoimmune diseases, transplants, and allergies..$^{50,69,70} \mathrm{In}$ this context, it is known that plasmacytoid type DC (pDC), that participate in the immune response and the generation of tolerance, can act in the DM1 in the control of the regulatory and pathogenic T cells. ${ }^{17,34}$

In order to develop therapies for DM1 using tolerogenic DC, a study was performed ablating the myeloid DC (mDC) and $\mathrm{pDC}$ mediated by diphtheria toxin receptor in nonobese diabetic mice (NOD). The results showed that, with the ablation of $\mathrm{mDC}$, prevention of the development of DM was achieved. However, with the ablation of pDC, an increase in the severity of the insulitis was observed, accompanied by the loss of natural killer T cells (NKT) and a decrease of IDO. Since IDO enzyme is an inhibitor of T cell response, the decrease of $\mathrm{pDC}$ or the inhibition of IDO by the use of 1-methyl-D-tryptophan (1-MT) increased the aggressiveness of the insulitis and the destruction of pancreatic $\beta$-cells. Also, the ablation of pDC caused reallocation of NKT cells that aggravates the insulitis, while the restoration of $\mathrm{pDC}$ normalized the insulin and NKT levels. The IFN- $\gamma$ secretion by the NKT induced IDO production by DC, interconnecting these responses. Finally, it was concluded that pDC, IDO, and NKT can act together to prevent insulin production and, consequently, the development of DM1.71,72

Another study demonstrated that NOD mice have a deficiency in the signaling and functioning of the IDO enzyme, even after stimulation of $\mathrm{pDC}$ with TGF- $\beta 1$. IDO could only be stimulated by this cytokine in the presence of a basal amount of this enzyme in the pDC. So, in order to initiate the phosphorylation cascade and the consequent protein signaling, it was necessary to perform a forced induction of the IDO in the pDC and the stimulation with TGF- $\beta 1$. IDO signaling generated a positive feedback with TGF- $\beta 1$, alternatively activating the NF- $\mathrm{KB}$ pathway. ${ }^{17}$

A recent study showed that a chimeric vaccine composed of the proinsulin and cholera toxin B subunit (CTB-INS) was able to suppress DM1 onset in NOD mice and upregulated enzyme IDO1 in human DC. This vaccine activated the tumor necrosis factor associated factor (TRAF) super-family receptor (TRAFR) pathway and led to the upregulation of IDO1 biosynthesis in CTB-INS inoculated DC. The control of NF-KB-inducing kinase (NIK) post-translational stability may be essential for the modulation of non-canonical NF- $\kappa B$ signaling pathway. Evidence suggests that TRAF2, TRAF3, and TRAF6 are critical to negative regulation of NIK activity. The CTB-INS vaccine acts in the TNF receptor-dependent signaling pathway of the noncanonical NF- $\mathrm{KB}$ signaling pathway resulting in the suppression of mediated DM1. ${ }^{73}$

DCs present autoantigens of pancreatic $\beta$-cells for selfreactive $\mathrm{T}$ lymphocytes. They are also involved in the deletion of autoreactive $\mathrm{T}$ cells. A report showed that targeting of DCs with beta cell antigens was able to achieve deletion of autoreactive cytotoxic T cells in NOD model. ${ }^{74}$

After treating DC with CTB-INS vaccine, an increase in the degradation of the TRP, a reduction in cell maturation functions, and an augment of the IDO1 synthesis were observed. This biosynthesis was reduced with NF- $\kappa B$ blockers reinforcing the role of this factor in the induction of IDO. All these findings, combined with the fact that this does not interfere with the monocytes differentiation into DC, open the possibility of developing safe and effective immunotherapeutic strategies for the prevention of autoimmunity that occurs in DM1. ${ }^{16}$

A clinical trial using DC for the treatment of DM1 is currently underway. ${ }^{75-79}$ The vaccine consists of autologous monocyte-derived DC treated ex vivo with antisense phosphorothioate-modified oligonucleotides targeting the primary transcripts of the CD40, CD80, and CD86 co-stimulatory molecules, generating DC with immunoregulatory properties. The safety Phase I study ${ }^{80}$ allowed to conclude that the use of tolerogenic DC in patients with DM1 was well accepted and safe, without adverse effects or toxicity. ${ }^{76}$ In Phase II, the modulatory capability of DC collected via leukapheresis and engineered ex vivo via incubation with antisense DNA oligonucleotides targeting the primary transcripts of CD40, CD80, and CD86 will be evaluated. ${ }^{80,81}$

\section{Final considerations}

Nowadays, DC therapies to DM1 have focus on the immunoregulatory properties of these cells through their maturation and on the action of the IDO, an enzyme that participates in the metabolism of TRP and causes accumulation of the metabolites of kynurenines and consequent blockade of T lymphocyte proliferation. As shown here, the use of DCs in cell therapies in DM1, although recent, already presents 
promising results since it has been proven that the IDO enzyme can be modulated in DC in a tolerogenic way. In this sense, it was possible to conclude that recent studies have demonstrated that DC expressing tolerogenic IDO may be effective in regulating the immune response of DM1. Therefore, the data support the suggestion of the application of tolerogenic DCs to induce tolerance in DM1. It is important to highlight that studies with DC on DM1 are in clinical phase and the results obtained heretofore are promising since they indicate the possibility of developing therapies for the treatment or prevention of the DM1. However, clinical trials are still in the initial phase and a more robust group of assays to confirm this proposition is necessary.

\section{Disclosure}

The authors report no conflicts of interest in this work.

\section{References}

1. Zhang CL, Zou XL, Peng JB, Xiang M. Immune tolerance induced by adoptive transfer of dendritic cells in an insulin-dependent diabetes mellitus murine model. Acta Pharmacol Sin. 2007;28(1):98-104.

2. Lakhtakia R. The history of diabetes mellitus. Sultan Qaboos Univ MedJ. 2013;13(3):368-370.

3. Godfrey KJ, Mathew B, Bulman JC, Shah O, Clement S, Gallicano GI. Stem cell-based treatments for type 1 diabetes mellitus: bone marrow, embryonic, hepatic, pancreatic and induced pluripotent stem cells. Diabet Med. 2012;29(1):14-23.

4. Bouwens L, Houbracken I, Mfopou JK. The use of stem cells for pancreatic regeneration in diabetes mellitus. Nat Rev Endocrinol. 2013; 9(10):598-606.

5. Lee CN, Lew AM, Wu L. The potential role of dendritic cells in the therapy of type 1 diabetes. Immunotherapy. 2013;5(6):591-606.

6. Mellor A. Indoleamine 2,3 dioxygenase and regulation of T cell immunity. Biochem Biophys Res Commun. 2005;338(1):20-24.

7. Mellor AL, Munn DH. IDO expression by dendritic cells: tolerance and tryptophan catabolism. Nat Rev Immunol. 2004;4(10):762-774.

8. Munn DH, Sharma MD, Lee JR, et al. Potential regulatory function of human dendritic cells expressing indoleamine 2,3-dioxygenase. Science. 2002;297(5588):1867-1870.

9. Favre D, Mold J, Hunt PW, et al. Tryptophan catabolism by indoleamine 2,3-dioxygenase 1 alters the balance of TH17 to regulatory T cells in HIV disease. Sci Transl Med. 2010;2(32):32ra36.

10. Xie FT, Cao JS, Zhao J, Yu Y, Qi F, Dai XC. IDO expressing dendritic cells suppress allograft rejection of small bowel transplantation in mice by expansion of foxp3+ regulatory T cells. Transpl Immunol. 2015; 33(2):69-77.

11. Mandik-Nayak L, Merlo L. IDO2: a pathogenic mediator of inflammatory autoimmunity. Clin Med Insights Pathol. 2016;9 (Suppl 1): 21-28.

12. Li F, Zhang R, Li S, Liu J. IDO1: an important immunotherapy target in cancer treatment. Int Immunopharmacol. 2017;47:70-77.

13. Prendergast GC, Metz R, Muller AJ, Merlo LM, Mandik-Nayak L. IDO2 in immunomodulation and autoimmune disease. Front Immunol. 2014;5:585.

14. Zhang Y, Ruan Y, Zhang P, Wang L. Increased indoleamine 2,3dioxygenase activity in type 2 diabetic nephropathy. $J$ Diabetes Complications. 2017;31(1):223-227.

15. Fallarino F, Volpi C, Zelante T, et al. IDO mediates TLR9-driven protection from experimental autoimmune diabetes. J Immunol. 2009;183(10): 6303-6312.
16. Mbongue JC, Nicholas DA, Zhang K, et al. Induction of indoleamine 2, 3-dioxygenase in human dendritic cells by a cholera toxin B subunitproinsulin vaccine. PLoS One. 2015;10(2):e0118562.

17. Pallotta MT, Orabona C, Bianchi R, et al. Forced IDO1 expression in dendritic cells restores immunoregulatory signaling in autoimmune diabetes. J Cell Mol Med. 2014;18(10):2082-2091.

18. Turley S, Poirot L, Hattori M, Benoist C, Mathis D. Physiological beta cell death triggers priming of self-reactive $\mathrm{T}$ cells by dendritic cells in a type-1 diabetes model. J Exp Med. 2003;198(10):1527-1537.

19. Faustman DL, Davis M. The primacy of CD8 T lymphocytes in type 1 diabetes and implications for therapies. J Mol Med(Berl). 2009; 87(12):1173-1178.

20. Szablewski L. Role of immune system in type 1 diabetes mellitus pathogenesis. Int Immunopharmacol. 2014;22(1):182-191.

21. Taylor MW, Feng GS. Relationship between interferon-gamma, indoleamine 2,3-dioxygenase, and tryptophan catabolism. FASEBJ. 1991; 5(11):2516-2522.

22. Mbongue JC, Nicholas DA, Torrez TW, et al. The role of indoleamine 2,3-dioxygenase in immune suppression and autoimmunity. Vaccines. 2015;3(3):703-729.

23. Huang L, Baban B, Johnson BA 3rd, Mellor AL. Dendritic cells, indoleamina 2,3 dioxygenase and acquired immune privilege. Int Rev Immunol. 2010;29(2):133-155.

24. Curti A, Trabanelli S, Salvestrini V, Baccarani M, Lemoli RM. The role of indoleamine 2, 3-dioxygenase in the induction of immune tolerance: focus on hematology. Blood. 2009;113(11):2394-2401.

25. Sugimoto H, Oda S, Otsuki T, Hino T, Yoshida T, Shiro Y. Crystal structure of human indoleamine 2,3-dioxygenase: catalytic mechanism of $\mathrm{O} 2$ incorporation by a heme-containing dioxygenase. Proc Natl Acad Sci U S A. 2006;103(8):2611-2616.

26. Mellor AL, Chandler P, Baban B, et al. Specific subsets of murine dendritic cells acquire potent $\mathrm{T}$ cell regulatory functions following CTLA4mediated induction of indoleamine 2,3 dioxygenase. Int Immunol. 2004; 16(10):1391-1401.

27. Munn DH, Sharma MD, Mellor AL. Ligation of B7-1/B7-2 by human CD4+ T cells triggers indoleamine 2,3-dioxygenase activity in dendritic cells. J Immunol. 2004;172(7):4100-4110.

28. Fatokun A, Hunt NH, Ball HJ. Indoleamine 2,3-dioxygenase 2 (IDO2) and the kynurenine pathway: characteristics and potential roles in health and disease. Amino Acids. 2013;45(6):1319-1329.

29. Moffett JR, Namboodiri MA. Tryptophan and the immune response. Immunol Cell Biol. 2003;81(4):247-265.

30. Allegri G, Costa CV, Bertazzo A, Biasiolo M, Ragazzi E. Enzyme activities of tryptophan metabolism along the kynurenine pathway in various species of animals. Farmaco. 2003;58(9):829-836.

31. Wirthgen E, Tuchscherer M, Otten W, et al. Activation of indoleamine 2,3-dioxygenase by LPS in a porcine model. Innate Immun. 2014;20(1): 30-39.

32. Fallarino F, Grohmann U, Puccetti P. Indoleamine 2,3-dioxygenase: from catalyst to signaling function. Eur J Immunol. 2012;42(8): 1932-1937.

33. Sarkar SA, Wong R, Hackl SI, et al. Induction of indoleamine 2,3dioxygenase by interferon-gamma in human islets. Diabetes. 2007; 56(1):72-79.

34. Pallotta MT, Orabona C, Volpi C, et al. Indoleamine 2,3-dioxygenase is a signaling protein in long-term tolerance by dendritic cells. Nat Immunol. 2011;12(9):870-878.

35. Huang H, Dawicki W, Zhang X, Town J, Gordon JR. Tolerogenic dendritic cells induce CD4+CD25hiFoxp3+ regulatory T cell differentiation from CD4+CD25-/loFoxp3- effector T cells. J Immunol. 2010;185(9): 5003-5010.

36. Morrow LE, Gogineni V, Malesker MA. Probiotic, prebiotic, and synbiotic use in critically ill patients. Curr Opin Crit Care. 2012;18(2): 186-191.

37. Poormasjedi-Meibod MS, Jalili RB, Hosseini-Tabatabaei A, Hartwell R, Ghahary A. Immuno-regulatory function of indoleamine 2,3 dioxygenase through modulation of innate immune responses. PLoS One. 2013; 8(8):e71044. 
38. Platten M, von Knebel Doeberitz N, Oezen I, Wick W, Ochs K. Cancer immunotherapy by targeting IDO1/TDO and their downstream effectors. Front Immunol. 2015;5:673.

39. Palego L, Betti L, Rossi A, Giannaccini G. Tryptophan biochemistry: structural, nutritional, metabolic, and medical aspects in humans. J Amino Acids. 2016;2016:8952520.

40. Basran J, Booth ES, Lee M, Handa S, Raven EL. Analysis of reaction intermediates in tryptophan 2,3-dioxygenase: a comparison with indoleamine 2,3-dioxygenase. Biochemistry. 2016;55(49):6743-6750.

41. Batabyal D, Yeh SR. Substrate-protein interaction in human tryptophan dioxygenase: the critical role of H76. J Am Chem Soc. 2009;131(9): 3260-3270.

42. Meng B, Wu D, Gu J, Ouyang S, Ding W, Liu ZJ. Structural and functional analyzes of human tryptophan 2,3-dioxygenase. Proteins. 2014;82(11):3210-3216.

43. Metz R, Rust S, Duhadaway JB, et al. IDO inhibits a tryptophan sufficiency signal that stimulates mTOR: A novel IDO effector pathway targeted by D-1-methyl-tryptophan. Oncoimmunology. 2012;1(9):1460-1468.

44. Munn DH, Mellor AL. Indoleamine 2,3 dioxygenase and metabolic control of immune responses. Trends Immunol. 2013;34(3):137-143.

45. Ravishankar B, Liu H, Shinde R, et al. The amino acid sensor GCN2 inhibits inflammatory responses to apoptotic cells promoting tolerance and suppressing systemic autoimmunity. Proc Natl Acad Sci U S A 2015;112(34):10774-10779.

46. Sonner JK, Deumelandt K, Ott M, et al. The stress kinase GCN2 does not mediate suppression of antitumor T cell responses by tryptophan catabolism in experimental melanomas. Oncoimmunology. 2016;5(12):e1240858.

47. Fallarino F, Grohmann U, You S, et al. The combined effects of tryptophan starvation and tryptophan catabolites down-regulate $\mathrm{T}$ cell receptor zeta-chain and induce a regulatory phenotype in naive $\mathrm{T}$ cells. J Immunol. 2006;176(11):6752-6761.

48. Fallarino F, Grohmann U, You S, et al. Tryptophan catabolism generates autoimmune-preventive regulatory T cells. Transpl Immunol. 2006 17(1):58-60

49. Hayashi T, Mo JH, Gong X, et al. 3-Hydroxyanthranilic acid inhibits PDK1 activation and suppresses experimental asthma by inducing $\mathrm{T}$ cell apoptosis. Proc Natl Acad Sci U S A. 2007;104(47):18619-18624.

50. Silva Pde M, Bier J, Paiatto LN, et al. Tolerogenic dendritic cells on transplantation: immunotherapy based on second signal blockage. J Immunol Res. 2015;2015:856707.

51. Sharma MD, Hou DY, Liu Y, et al. Indoleamine 2,3-dioxygenase controls conversion of Foxp3+ Tregs to TH17-like cells in tumor-draining lymph nodes. Blood. 2009;113(24):6102-6111.

52. Platten M, Ho PP, Youssef S, et al. Treatment of autoimmune neuroinflammation with a synthetic tryptophan metabolite. Science. 2005; 310(5749):850-855.

53. Eleftheriadis T, Pissas G, Antoniadi G, Liakopoulos V, Stefanidis I. Indoleamine 2,3-dioxygenase depletes tryptophan, activates general control non-derepressible 2 kinase and down-regulates key enzymes involved in fatty acid synthesis in primary human $\mathrm{CD}^{+} \mathrm{T}$ cells. Immunology. 2015;146(2):292-300.

54. Belladonna ML, Orabona C, Grohmann U, Puccetti P. TGF- $\beta$ and kynurenines as the key to infectious tolerance. Trends Mol Med. 2009; $15(2): 41-49$

55. Barth H, Raghuraman S. Persistent infectious diseases say - IDO. Role of indoleamine-2,3-dioxygenase in disease pathogenesis and implications for therapy. Crit Rev Microbiol. 2014;40(4):360-368.

56. Lewkowicz N, Klink M, Mycko MP, Lewkowicz P. Neutrophil CD4+CD25+ T regulatory cell interactions: a possible new mechanism of infectious tolerance. Immunobiology. 2013;218(4):455-464.

57. Zoso A, Mazza EM, Bicciato S, et al. Human fibrocytic myeloid-derived suppressor cells express IDO and promote tolerance via Treg-cell expansion. Eur J Immunol. 2014;44(11):3307-3319.

58. Tu L, Chen J, Zhang H, Duan L. Interleukin-4 inhibits regulatory T cell differentiation through regulating CD103+ dendritic cells. Front Immunol. 2017;8:214.

59. Fischbach MA, Bluestone JA, Lim WA. Cell-based therapeutics: the next pillar of medicine. Sci Transl Med. 2013;5(179):179ps7.
60. Garcia O, Carraro G, Navarro S, et al. Cell-based therapies for lung disease. Br Med Bull. 2012;101:147-161.

61. Voltarelli JC, Couri CE, Rodrigues MC, et al. Terapia celular no diabetes mellitus. Rev Bras Hematol Hemoter. 2009;31:149-156.

62. Assady S, Maor G, Amit M, Itskovitz-Eldor J, Skorecki KL, Tzukerman M. Insulin production by human embryonic stem cells. Diabetes. 2001;50(8):1691-1697.

63. Jalili RB, Forouzandeh F, Rezakhanlou AM, et al. Local expression of indoleamine 2,3 dioxygenase in syngeneic fibroblasts significantly prolongs survival of an engineered three-dimensional Islet allograft. Diabetes. 2010;59(9):2219-2227.

64. Herold KC, Hagopian W, Auger JA, et al. Anti-CD3 monoclonal antibody in new-onset type 1 diabetes mellitus. N Engl JMed. 2002;346(22): 1692-1698.

65. Keymeulen B, Vandemeulebroucke E, Ziegler AG, et al. Insulin needs after CD3-antibody therapy in new-onset type 1 diabetes. $N$ Engl J Med. 2005;352(25):2598-2608.

66. Couri CE, Foss MC, Voltarelli JC. Secondary prevention of type 1 diabetes mellitus: stopping immune destruction and promoting beta-cell regeneration. Braz J Med Biol Res. 2006;39(10):1271-1280.

67. Stracieri AB, Oliveira MC, Simo BP, et al. Autologous nonmyeloablative hematopoietic stem cell transplantation in newly diagnosed type 1 diabetes mellitus. JAMA. 2007;297(14):1568-1576.

68. Vanikar AV, Trivedi HL, Thakkar UG. Stem cell therapy emerging as the key player in treating type 1 diabetes mellitus. Cytotherapy. 2016; 18(9):1077-1086.

69. Steinman RM. Dendritic cells: understanding immunogenicity. Eur J Immuno. 2007;37 (Suppl 1):S53-S60.

70. Steinman RM, Banchereau J. Taking dendritic cells into medicine. Nature. 2007;449(7161):419-426.

71. Saxena V, Ondr JK, Magnusen AF, Munn DH, Katz JD. The countervailing actions of myeloid and plasmacytoid dendritic cells control autoimmune diabetes in the nonobese diabetic mouse. $J$ Immunol. 2007;179(8):5041-5053.

72. Nikolic T, Welzen-Coppens JM, Leenen PJ, Drexhage HA, Versnel MA. Plasmacytoid dendritic cells in autoimmune diabetes - potential tools for immunotherapy. Immunobiology. 2009;214(9-10):791-799.

73. Kim NS, Mbongue JC, Nicholas DA, et al. Chimeric vaccine stimulation of human dendritic cell indoleamine 2, 3-dioxygenase occurs via the non-canonical NF-אB pathway. PLoS One. 2016;11(2):e0147509.

74. Mukhopadhaya A, Hanafusa T, Jarchum I, et al. Selective delivery of cell antigen to dendritic cells in vivo leads to deletion and tolerance of autoreactive CD8+ T cells in NOD mice. Proc Natl Acad Sci U S A. 2008;105(17):6374-6379.

75. Eibl N, Spatz M, Fischer GF, et al. Impaired primary immune response in type-1 diabetes: results from a controlled vaccination study. Clin Immunol. 2002;103(3 Pt 1):249-259.

76. Giannoukakis N. Phase I (safety) study of autologous tolerogenic dendritic cells in type 1 diabetic patients. Diabetes Care. 2011;34(9): 2026-2032.

77. Huo W, Li GH, Qi RQ, et al. Clinical and immunologic results of local hyperthermia at $44^{\circ} \mathrm{C}$ for extensive genital warts in patients with diabetes mellitus. Int J Hyperthermia. 2013;29(1):17-20.

78. Gottlieb PA, Alkanani AK, Michels AW, et al. $\alpha 1$-Antitrypsin therapy downregulates toll-like receptor-induced IL-1 $\beta$ responses in monocytes and myeloid dendritic cells and may improve islet function in recently diagnosed patients with type 1 diabetes. J Clin Endocrinol Metab. 2014;99(8):E1418-E1426.

79. Orban T, Beam CA, Xu P, et al. Reduction in CD4 central memory $\mathrm{T}$-cell subset in costimulation modulator abatacept-treated patients with recent-onset type 1 diabetes is associated with slower C-peptide decline. Diabetes. 2014;63(10):3449-3457.

80. Giannoukakis N, Phillips B, Finegold D, Harnaha J, Trucco M. Phase I (safety) study of autologous tolerogenic dendritic cells in type 1 diabetic patients. Diabetes Care. 2011;34(9):2026-2032.

81. Harnaha J, Machen J, Wright M, et al. Interleukin-7 is a survival factor for CD4+ CD25+ T-cells and is expressed by diabetes-suppressive dendritic cells. Diabetes. 2006;55(1):158-170. 


\section{Publish your work in this journal}

Drug Design, Development and Therapy is an international, peerreviewed open-access journal that spans the spectrum of drug design and development through to clinical applications. Clinical outcomes, patient safety, and programs for the development and effective, safe, and sustained use of medicines are the features of the journal, which

has also been accepted for indexing on PubMed Central. The manuscript management system is completely online and includes a very quick and fair peer-review system, which is all easy to use. Visit http://www.dovepress.com/testimonials.php to read real quotes from published authors.

Submit your manuscript here: http://www.dovepress.com/drug-design-development-and-therapy-journal 